\title{
The New, New Economics And Monetary Policy
}

\author{
A speech given by DARRYL R. FRANCIS, President, Federal Reserve Bank \\ of St. Louis, to the Argus Economic Conference, Phoenix, Arizona \\ November 22, 1969
}

I

T IS GOOD to have this opportunity to keynote these seminars you will be attending for the next few days. Before proceeding to what I have to say about "The New, New Economics and Monetary Policy," let me place the two uses of the term "New" in their proper perspective.

The expression "New Economics" has been applied to the body of economic theory popularly called "Keynesian Economics." This theory was set forth by John Maynard Keynes in 1936 and has been in vogue among economists since the 1940 's. Economic policymakers in the 1960's have made great use of the "New Economics" as guidance for their actions.

The early followers of Keynes stressed the view that chronic unemployment is a characteristic of our economy. This view was consistent with the mass unemployment of the 1930's. The business fuctuations which continued in the late 1940 s and $1950^{\circ} \mathrm{s}$ led many followers of the New Economics to conclude that our economy is basically unstable - subject to shifts between periods of recession and inflation. These two conclusions - that unemployment is a chronic problem and that our economy is basically unstable - resulted in the proposition that vigorous Government actions are necessary to promote high level employment, economic growth, and relatively stable prices. This proposition is embodied in the spirit of the Employment Act of 1946.

This view was accepted by the President's Council of Economic Advisers from 1960 to 1968 . The tax cut of 1964 and the tax increase of 1968 are the hallmark of the "New Economics." The "New Economics" is a combination of depression-oriented theories and expansionist objectives. Such a combination contains an inherent inflationary bias which should be carefully considered when it is applied to national economic policy.

Let us now examine the other use of the word "New." The body of economic theory which we will study in these seminars is not something new tacked on to the basic analytical framework of the New Economics. Instead, it is an up-dated version of the economic theory which was dominant for many decades prior to what has been labeled the "Keynesian Revolution." The older economics held that our economic system is inherently stable; hence, there was little need for vigorous stabilization actions on the part of Government. In fact, Government was viewed as a source of economic instability. The expression "New, New Economics" refers to a revival and elaboration of this pre-Keynesian body of economic theory. This development has been accelerating during the past few years because of the failures of stabilization policy based on the major premises of the New Economics.

I now turn to my main topic, "The New, New Economics and Monetary Policy." My remarks will be built around three points: First, the two competing views of monetary and fiscal actions in economic stabilization are outlined, and evidence is presented which, I believe, has led most of the economists who will deliver presentations at these seminars to assign great importance to monetary actions. Next, 
there is an examination of the slow response of inflation to recent monetary restraint. Finally, the problem of reducing the rate of inflation without a great reduction in output of goods and services and a marked increase in unemployment is considered.

\section{Two Views of Monetary and Fiscal Actions}

I will now contrast the two views of monetary and fiscal actions. The basic premise of the "New, New Economics" is that the Federal Reserve System, through its control of the money stock, exercises a pervasive influence on the course of total spending, that is, gross national product, and thereby on prices. On the other hand, Federal Government spending and taxing actions, alone, are held to exert little net influence on movements in GNP and prices.

For example, an increase in the rate of Government spending at a time when the money stock remains unchanged requires either of two methods of financing - taxing or borrowing from the public. In either case, spending by the private sector is reduced by an amount approximately equal to the rise in Federal Government expenditures, resulting in little, if any, change in the rate of overall spending in the economy. However, if the Federal Reserve System makes it possible for the banking system to acquire sufficient Government debt to permit financing a rise in Government expenditures without taxing or borrowing from the public, total spending will increase. In this case, the money stock increases and is more properly considered the cause of increased spending.

These observations regarding fiscal policy have been recognized by both Keynesians and proponents of the "New, New View," except that Keynesians have not assigned an important role to money. Unfortunately, however, this point regarding fiscal actions has received little recognition in the formulation of stabilization policies or in recently constructed econometric models of our economy from which many policymakers obtain information. Instead, Government spending and taxing have been considered extremely powerful tools of economic stabilization, regardless of the source of funds to finance a deficit or of the disposition of a budget surplus. As a result, fiscal policy in my opinion has been given too great an emphasis and has had a misguiding influence in monetary policy formulation.

I now come to monetary actions - the point at which the New, New Economics differs greatly from the school of economic thought prevailing since the mid-1930's. Early Keynesians held that changes in the money stock, unless accompanied by appropriate changes in Government spending, have little influence on GNP. Monetary policy was assigned only a passive, supporting role to fiscal policy. This view - that there is little independent influence of monetary actions on total spending - was widely accepted up to the mid1960's and has played a dominant role in the formulation of economic stabilization policies, even up to now.

The New, New Economics directly challenges the validity of this proposition. Historical evidence strongly supports this challenge! Whenever growth of the money stock indicates one direction of movement for GNP and the Government's budget another, the subsequent course of GNP in virtually every case follows that indicated by money. There are two important pieces of recent evidence supporting this monetary view, One is the mini-recession experience following the monetary restraint of 1966 - when money remained unchanged and the budget moved into greater deficits. The other one is the failure of fiscal restraint which began in mid-1968 - a time when money continued to increase at an excessive rate. Another piece of evidence is provided by the Great Depression of the $1930^{x} s$, when economic activity followed more closely the course indicated by movements in the money stock than the one indicated by the Government's budget.

This evidence, along with that provided by many detailed studies, in my opinion demonstrates that monetary actions measured by changes in the money stock should receive the main emphasis in economic stabilization. To ignore the influence of monetary actions is to insure disruption of our normal, orderly economic processes. History demonstrates that most of our recessions and periods of inflation can be attributed to perverse movements in the money stock. For example, the Great Depression was marked by an 8 per cent annual rate of decrease in money during the four years after mid-1929.

\section{Slow Response to Recent Monetary Restraint}

I now turn to my second main point, the apparently slow response of inflation to recent monetary restraint. We have had an avowed policy of monetary restraint for nearly a year, but there is only scattered evidence at present that the overall pace of inflation has begun to recede. Some have started to question whether monetary restraint will prove to be as ineffective in curbing the current inflation as did fiscal restraint in 
the past year and a half. Two things can account for the slow response of inflation to the restrictive monetary policy adopted last December.

First, only in the past six months has there been what may be characterized as substantial monetary restraint The rate of monetary expansion was reduced in two stages from the excessive 7 per cent annual rate of 1967 and 1968. The rate of growth in the money stock was reduced to about 5 per cent for the first five months of this year, and since then money has not increased. This latter development is one which I would call substantial monetary restraint.

Second, there is a considerable lag in the response of the economy to a change in the rate of monetary expansion. At the St. Louis Federal Reserve Bank our staff has conducted an extensive investigation to uncover the nature of this lag, using the New, New Economics' frame of reference. Although this research is not quite fininshed, I would like to share with you our findings up to now. ${ }^{1}$

This research indicates that, following a marked decrease in the rate of growth in money, at least two quarters are required for a noticeable reduction in GNP growth. When total spending does finally slow, growth of output of goods and services slows simultaneously, but at least an additional three quarters are generally required for a marked reduction in the rate of inflation to appear. We estimate that the entire process of curbing inflation would normally require about three years. Our research further indicates that the process of fully curbing inflation is delayed still longer when monetary restraint is implemented after a period of prolonged and accelerating price advances.

This is the situation which currently confronts efforts to reduce the rate of price increases. We have now had an obvious and accelerating inflation for about five years. As a result, many economic decisions are based on expectations of continued inflation. For example, union leaders seek higher wages in part to protect workers' earnings from continued inflation, and business firms expect to be able to pay the higher wages by being able to increase their prices. Also, contracts to borrow funds take into consideration expectations of future inflation, thereby adding an inflation premium to market interest rates. Our research indicates that on the average it may take about five years of decelerating price increases to eliminate most of the expectations of continued inflation.

\footnotetext{
This research will be summarized in a forthcoming issue of this Review.
}

Given the normal response of the economy to slower growth in money, the entrenched expectations of continued inflation, and the beginning of really firm monetary restraint only six months ago, I am not disturbed that we have not yet seen a slowdown in the rate of price increases. There is some evidence of the slowing of growth of total spending and real product in recent monthly statistics. Personal income in September and October grew at only half the rate of the previous year. Industrial production in the last three months has declined at a 3 per cent annual rate after increasing at a 5 per cent rate in the previous year. Retail sales have been about unchanged since last spring, and in real terms have of course declined.

What has been accomplished thus far has been setting of the stage for a reduction in the rate of inflation. Consequently, at least the next three years will be required to eliminate a significant portion of this inflation. In response to recent monetary restraint, assuming it is continued or relaxed only moderately, we believe that gross national product and real output have begun to grow at a slower pace. We believe that there will be further marked slowing in 1970, and that the rate of inflation will have been moderated significantly by late 1971. But even at that point, additional time will be required before we will have reduced inflation below a two per cent rate. With continuation of inflation for some time to come, interest rates, because of the inflation premium mentioned earlier, are not likely to decrease much in the near future.

If the results of this research into the nature of the response of output and prices to monetary actions are nearly correct, I have just outlined the extreme problem that lies ahead. A high degree of moral, economic, and political fortitude will be required if we are to overcome the increasingly painful results of the New Economics' guidance of policy during the last several years.

\section{Curbing Inflation Without a Recession}

I now come to my last main point, the problem of curbing inflation without causing a recession. I believe most economists will agree with the proposition I have just advanced - that whenever the rate of growth in total spending decreases for several quarters, real output of goods and services will also grow at a reduced rate, while the rate of price increases will respond only with a considerable lag. Moreover, there is general agreement that, if total 
spending slows sufficiently, real output will actually decrease and a recession develop. It is obvious that in developing a strategy for curbing inflation, monetary authorities face the difficult choice of balancing a desire to avoid inordinate decreases in real output against a desire to curb inflation in as short an interval of time as possible. This choice is made more difficult by the long time required to curb inflation, regardless of whether or not a recession occurs, after such a long period of inflation as we are currently experiencing.

The present situation bears careful watching that we not maintain the present degree of monetary restraint too long. If we continue much longer to hold the money stock at about its level of early last summer, I am concerned that the economy will exm perience an unnecessarily severe decrease in output next year accompanied by high unemployment before much progress is achieved in slowing inflation. The recent research at our bank indicates that there is little difference in our ability to reduce the rate of inflation over the next three years if money were to grow at a moderate 3 per cent rate from now than if it were held unchanged for several months longer. With a 3 per cent rate of growth in money beginning soon, we would have a risk of a slight recession, while if money remains unchanged much longer, real output is likely to decrease at about a 3 per cent rate next year. In either case, unemployment will rise, but the extent and duration of higher unemployment will be considerably less if a course of moderate growth in money is now adopted.

If a substantial recession were to show signs of developing as a result of an excessive duration of the present level of restraint, I am concerned that there would develop public pressures to expand money once again at such excessive rates as have prevailed during much of the past five years. An examination of the experience of 1967 and 1968 demonstrates the results of such actions. After the money stock remained unchanged for the last nine months of 1966 , the rate of total spending slowed during the first two quarters of 1967, and real output declined slightly in the first quarter of that year. Hoping to avoid overkill, monetary authorities resumed money supply growth at an excessive 7 per cent rate and, thus, stimulated inflation further.

It was entirely proper that money growth should have been resumed at that time; if it had remained unchanged much longer, there would have been a significant recession in 1967 . We estimate that if money growth had been resumed at a moderate 3 per cent rate - the rate which from 1961 to 1964 got the economy out of the previous recession - the rate of inflation would have been about 2 per cent at the present time, instead of the current rate of 5 to 6 per cent. Moreover, achievement of price stability would have been virtually assured for next year. With a slower rate of inflation, long-term interest rates would have been about 2 percentage points lower today. If we once again succumb to pressures for excessive rates of monetary expansion, we will again have lost the battle against inflation, as in 1967 and 1968.

\section{Conclusion}

In conclusion, I am sorry that I cannot present to you a view which maintains that inflation is fairly easy to conquer within a year or so. We should remember that our present inflation was permitted to develop at an accelerating rate over the past five years. It is rather presumptuous to assume that this trend can be reversed in a year or so, or that the cooling-off of inflation can be achieved in a reasonable time without a period of very slow growth in output and higher unemployment. Overly optimistic pronouncements of our ability to curb the present inflation in a hurry and with only slight effects on employment are a disservice to our people and a stumbling block to the working of orderly corrective processes.

I want to point out that in the 1950 's about 7 years of restraint on spending and output were required to eliminate the inflation which accompanied the Korean War. Three recessions occurred during this period as the result of stop-and-go monetary expansion which alternated between periods of rapid growth and decrease in money. Inflation has now been more intense than in the $1950^{\circ} \mathrm{s}$, making the problem even more difficult. However, if moderate but persistent monetary restraint is applied, avoiding the stop-andgo policies of previous efforts to curb inflation, perhaps inflation may be eliminated somewhat sooner this time without subjecting the economy to wide variations in output of goods and services and in employment.

This does not mean that monetary actions cannot produce the desired results. Instead, it means that all segments of our society must have patience while these actions are conducted, so as to permit the 
economy to achieve non-inflationary growth in output of goods and services. Such growth, according to the New, New Economics, will be at a rate determined by normal growth in the productive capacity of our economy. Once we have achieved this goal, monetary actions must be conducted in such a manner as to assure that they will not be a source of future economic instability.

Many individuals have become impatient at the slow progress made in curbing inflation and have been urging the imposition of price and wage controls. Recently, there has been considerable support for selective credit controls. Such measures, even if cloaked with pseudo-respectability by being placed on a voluntary basis for a brief period, are not part of the New, New Economics. Instead, we believe that the best way to cure our nation's economic ills is to allow stabilization efforts to work their influence through our relatively free, competitive market system. Moreover, experience during World War II and the Korean War has demonstrated that treating only the symptoms of inflation is neither effective nor desirable. Also, reliance on such controls could very well lead to their being substituted for appropriate overall stabilization policy. Such was the experience with the use of price-wage guidelines during the escalation phase of the Vietnam War.

Finally, experience reinforces the belief held by many that an inflationary trend should never be permitted to start because of the great inequities it creates and because of the long and arduous effort which is required to conquer it. Some argue that inflation is a small price to pay for a high level of employment for all segments of our society. This may be a basic tenet of the New Economics; but it is not a tenet of the economic school of thought represented at these seminars. The New, New Economics holds that inflation is not required, and indeed is not a long-run effective means, for our economy to grow at its productive potential or for the achievement of a high level of employment.

This article is avalable as Reprint No. 50.

SUBSCRIPTIONS to this bank's REvew are available to the public without charge, including bulk mailings to banks, business organizations, educational institutions, and others. For information write: Research Department, Federal Reserve Bank of St. Louis, P. O. Box 442, St. Louis, Missouri 63166. 